November 30: President, Sir William Bragg; Treasurer, Sir Henry Lyons; Secretaries, Sir Frank Smith and Prof. A. V. Hill ; Foreign Secretary, Prof. A. C. Seward ; Other members of Council, Prof. E. D. Adrian, Mr. D. L. Chapman, Prof. A. W. Conway, Dr. W. H. Eccles, Prof. A. S. Eve, Prof. L. N. G. Filon, Dr. J. Gray, Sir Daniel Hall, Dr. S. W. Kemp, Sir Patrick Laidlaw, Sir Gerald Lenox-Conyngham, Prof. G. T. Morgan, Prof. R. Robison, Dr. Bernard Smith, Prof. W. Stiles, Mr. W. Trotter.

\section{Dr. P. Kapitza's Apparatus and the U.S.S.R.}

A REPORT published on November 19 in the Cambridge University Reporter gives an account of a proposed arrangement for the transfer of apparatus from the Royal Society Mond Laboratory at Cam. bridge to a new laboratory which is being built for Dr. P. Kapitza in the U.S.S.R. It will be remembered that Dr. Kapitza was refused leave to return to England after his visit to Russia in September 1934. In the report of the Committee for the Laboratory, it is pointed out that much of Dr. Kapitza's work in Cambridge had been preliminary to the experiments with strong magnetic fields at the temperature of liquid helium which he was on the point of beginning before he left for Russia, and that members of the Laboratory would not care to take up these experiments if Dr. Kapitza wished to resume work at once in this field. It is therefore suggested that the large generator for the production of strong magnetic fields, together with its associated apparatus, should be sold to the Government of the U.S.S.R. for the use of Dr. Kapitza. The remainder of the apparatus in the Laboratory, including the apparatus for the production of liquid hydrogen and liquid helium, would not be transferred since it is in constant use and will be required for the future work of the laboratory. It is proposed, however, to supply duplicates of this apparatus for transfer to Russia, so that Dr. Kapitza will have equipment identical with that he had developed in Cambridge. With the sum received for this apparatus it is proposed to buy new equipment suitable for the future work of the Laboratory. Such equipment might include a large electromagnet which could be used for nuclear research or for the production of low temperatures by the method of adiabatic demagnetisation.

\section{Prof. Ejnar Hertzsprung}

IN connexion with the recent announcement that Prof. Ejnar Hertzsprung, professor of astrophysics in the University of Leyden, and assistant director of the Leyden Observatory, has been appointed director of the Observatory to succeed the late Prof. W. de Sitter, it may be recalled that Prof. Hertzsprung was awarded the Gold Medal of the Royal Astronomical Society in 1929. Prof. Hertzsprung's work covers an extremely wide range of astronomical subjects, and he has contributed to our knowledge in nearly every branch of the science. In particular, he is known for his work on double stars and on the clusters. The mass luminosity relation, the division of the late type stars into giants and dwarfs, and the connexion between absolute magnitude and spectral type (the famous 'seven diagram') are all associated with his name (together with that of Prof. H. N. Russell, of Princeton). He will have as his assistant director at Leyden, Dr. J. Oort, who is also well known in Great Britain, chiefly on account of his work on galactic rotation.

\section{"Everyday Science" and Civil Service Examinations}

For several years "Everyday Science" has been one of the obligatory subjects of the competitive examinations for the important administrative group of Government services, comprising the Indian and Ceylon Civil, the Foreign Office and Diplomatic, the Consular and Overseas Trade (Intelligence Officer) and Home Civil (Junior Grade of the Administrative Class). We notice with astonishment and regret, therefore, the announcement of the Civil Service Commissioners that, with effect from next year, the subject will be omitted; some optional questions on science will be included under the subject "Present Day". The scope of the "Everyday Science" paper, now to be discontinued, is indicated by the following passage: "Such knowledge will be expected as candidates will have who have studied science intelligently at school and have since then kept their eyes open. A liberal choice of questions will be given. Attention should be paid to orderly, effective, and exact expression". The other parts of the obligatory section of the examination are : Essay, English ("to test the understanding of English and the workmanlike use of words"), "Present Day" (being questions on contemporary subjects, social, economic and political, calling for effective and skilful exposition), auxiliary language and viva voce. The inclusion of "Everyday Science" must have exerted an influence on school and college courses, and its omission will be regretted by many who believe in the value of "general science" teaching in schools and hold it to be plainly wrong (to quote the words of Mr. C. M. Bowra in Time and Tide's recent university supplement on "More and More of Less and Less") that highly educated men should know next to nothing of the structure of the universe or of their own bodies.

\section{Royal Institution: Legacy of the late Mr. Harry Brown}

From a statement recently issued by the Managers of the Royal Institution, it is understood that the munificent bequest to the Institution by the late Mr. Harry Brown, of the residue of his estate, reported in April last, is expected to amount to approximately $£ 28,000$. This large sum has been given without restriction as to its use, but the Managers hope to apply it mainly to the extension of experimental research, one of the two principal objects of the Institution's work. Shortly after information as to the legacy had been received, the freehold of 19 Albemarle Street, immediately adjoining the Davy Faraday Research Laboratory and the rest of the Institution's buildings, came into the market. With the double object of investing Mr. Brown's legacy and providing for future extensions of the premises, it was resolved to purchase the property. The 